\title{
Exploring The Influences on Cyber Education in a Bilingual Higher
}

\section{Institution}

\author{
Simon Wong ${ }^{1, *}$ \\ ${ }^{1}$ Hong Kong Community College, The Hong Kong Polytechnic University, Hong Kong \\ ${ }^{1}$ ccswong@hkcc-polyu.edu.hk*; \\ * corresponding author
}

\begin{abstract}
This paper presents the research study which explores the variables influencing the learning effectiveness of the students taking an online introductory information technology course in cyber education in a bilingual higher education institution in Hong Kong. These variables are: (1) student's English proficiency, (2) instructor's guidance in an online discussion forum and (3) peer students' collaboration in an online discussion forum. Correlation analysis was adopted to identify whether any of these variables could be potential factors on the students 'learning performance while multiple regression analysis was performed to explore the combined effect of these variables on the students' learning performance. Validity and reliability of this research study are highlighted in this paper. Finally, the research findings are discussed.
\end{abstract}

Keywords: Cyber education; learning effectiveness; students' English proficiency; instructors' guidance; students' collaboration; online discussion forums;

\section{Introduction}

Wong [31] carried out a quasi-experiment for the introductory information technology (IT) course in a Hong Kong higher education college (in short, the college), which offers Associate Degree and Higher Diploma programs for graduates from secondary schools, for the four semesters in the years 2006 to 2008 to explore whether the students could learn more effectively, less effectively or equally effectively reflected by their test scores including education in comparison to classroom teaching. The participating students were randomly assigned to one of the three teaching methods: the students in teaching method 1 had to attend both lectures and tutorials in classrooms, the students using teaching method 2 did not attend lectures or tutorials in classrooms. They mainly learned through viewing the materials in the college's cybereducation system by themselves and discussed with other students and instructors in the discussion forum in the cybereducation system. The students using teaching method 3 were not required to attend lectures, but they were required to attend tutorials only and read through the materials posted in the college's cybereducation system. There are two major findings of this quasi-experiment. First, the leverage test score of the introductory IT course attained by the students in classroom teaching (teaching method 1) is close to the average test score attained by the students taking the online introductory IT course with instructors' guidance in tutorials (teaching method 3). Second, the students' average test score in teaching method 1 or teaching method 3 is significantly higher than the students' average test score in the teaching method using online integrated IT course without instructors' guidance (teaching method 2).

\subsection{Research Problem}

Wong [32] noted the findings of the quasi-experiment are different from many other findings [2, 4, 13, 30]. For example, unlike Wong's [31] findings, Lim et al [13] reported that the students in on-line instruction (teaching method 2) and the combined mode (teaching method 3) learn better than the students in classroom teaching (teaching method 1). Long [32] explained that the difference lies in the different media of instruction and cultural difference. In the quasi-experiment, the college students are mostly Chinese and learned with the less familiar English language. This is a characteristic in Hong Kong higher education as using English as a medium of instruction in Hong Kong. Higher education is to enhance students' English proficiency [28]. The main reasons for enhancing students' English proficiency are keeping a high standard of English helps to maintain the international trading power in Hong Kong 
$[9,10]$ and proficiency in English can help to grasp the primary significant studies in many disciplines, mostly written in English [24]. In the other studies e.g. [2, 4, 13, 30], the participating students did not learn with less familiar language.

Chin et al [17] noticed that Asian students are generally more willing to participate in online discussion because they are not required to response instantly with their less familiar English language and use their familiar languages in the discussion forum. However, Wong [32] noted that students 'messages in the discussion forum require instructors' clarification. So, instructors 'guidance in the discussion forum may be helpful to the students' learning.

In these regards, the researcher hypothesized that (1) student's English proficiency, (2) instructor's guidance in online discussion forum (or simply, online instructor guidance) and (3) peer students' collaboration in online discussion forum (or simply, online collaboration ) contribute to the student's online learning. The English proficiency could be measured by English proficiency marks which were based on Hong Kong Examinations and Assessment Authority's 2007 and 2008 survey results on the equivalence between Hong Kong public English examination (eg Hong Kong Certificate of Education Examination (HKCEE)) grades and the International English Language Testing System (IELTS) scores. The English proficiency was converted from the highest grades or scores of the students' public English examination results. The online instructor guidance could be operationalized by the number of relevant messages posted by the instructors and viewed by the students in the college's online discussion forum. The online collaboration could be operationalized by number of the peer students' posted relevant guidance messages read by the students in the discussion forum. Since the college's cyber education system recorded which forum messages were read by a system user, a college student could check the number of his or her viewed forum messages.

Other potential factors such as IT literacy, motivation and learning strategies may also contribute to students 'online learning, but the researcher focused on investigating student's English proficiency, online instructor guidance and online collaboration because their effect on the students' online learning might help to explore the difference between the findings of the quasi-experiment and many other comparative studies.

\subsection{Research Aims and Questions}

The proposed research aimed to investigate whether students 'English proficiency, online instructor guidance and online collaboration influences the college students' online learning. For this research aim, the following research questions were addressed:

1) How is each of the variables (i.e., student's English proficiency, online instructor guidance and online collaboration) correlated with the students' learning as reflected by their test scores through teaching methods 1,2 and 3 ?

2) How well do the variables predict the students' learning as reflected by their test scores through teaching methods 1,2 and 3? How much variance in the students' learning can be explained by these variables through teaching methods 1,2 and 3 ?

3) What is the distribution of the students' views on comparing the learning effectiveness of the three teaching methods and comparing the importance of the variables?

\subsection{Significance of the Study}

The significance of the proposed research is threefold. First, the proposed research investigated the students' learning performance which reflects important pedagogical quality of cybereducation. Second, this research explored how students' English proficiency is related to their online learning. Student's English proficiency helps students 'learning in classroom setting $[6,12]$, but the researcher was not aware of any studies in the literature that explored how student's English proficiency is related to students' learning in cybereducation when designing this research. Third, some previous studies e.g. $[1,8,18,26]$ found a relationship between online learning and any of online guidance and collaboration. This research furthered the understanding of how online instructor guidance and online collaboration are related to online learning in the context of Hong Kong higher education. 


\section{The Proposed Method/Algorithm}

In this research, the researcher used statistical methods to find relationship between the predictor variables (i.e. students 'English proficiency, online instructor guidance and online collaboration) and the students' test scores obtained in Wong's experiment [31].

\subsection{Data Collection}

The researcher used a stratified random sampling with proportional allocation [23] to select 75 participating students from each of the three groups in Wong's quasi-experiment [31]. The participants were invited to complete the online inquiry developed by the researcher for this study. Some questions, starting from question number 11, of the online questionnaire listed in Appendix. The sample size 75 for each stratum was based on the threshold $\mathrm{N}>50+8$ vproposed by Tabachnick and Fidell [3] for the sample size in multiple regression, where vis the number of predictor variables. As multiple regression was used later and three predictor variables were involved in the analysis in this study, the researchers used the sample size 75 which is larger than the threshold $50+8 \times 3=74$.

However, the use of questionnaires undergoes a rather low response rate. As advised by Saunderset al. [22], the researcher called respondents to meet, explained the purpose of collecting data through questionnaires, and got the questionnaires completed in the meet wanted order to improve response rate. Also, the researcher checked with the participants' accounts in the college's cyber education system in order to ensure that the participants entered the questionnaire correctly and honestly.

\subsection{Maintaining the Integrity of the Specifications}

Correlation analysis was performed using the Statistical Package for the Social Sciences version 17.0 (SPSS) to identify the potential factors by locating the variables that have a positive correlation with the students' test scores. The researcher also addressed statistical power by adopting the significance level to test the significance of the correlation coefficient and measure the reliability of the findings about the population of the college students based on the sample. Multiple regression analysis was also performed using SPSS to explore the combined effect of the three predictor variables on the students' test scores. The researcher used both simultaneous multiple regression and sequential multiple regression as they are useful for explanatory research to determine the extent to which the predictor variables influence the outcome variable [34].

\subsection{Validity and Reliability}

In this research design, two validities were involved. They are statistical conclusion validity and construct validity. Statistical conclusion validity refers to the validity with which a researcher can infer how two variables are related [19]. The analytical results in this quantitative phase showed the relationship between students' learning and the variables. Making inference about the relationship involves inferential statistics such as hypothesis testing. For the case in this study, the null hypothesis was there is no relationship between any or all of the independent variables (ie, students' English proficiency, online instructor guidance and online collaboration) and the dependent variable students' learning as reflected by the students' test scores. The significance values or probability value (p-value) generated by SPSS indicated whether the analytical results are statistically significant and valid.

Construct validity is the extent to which the construct is accurately measured in the study. This depends highly on how the construct is operationalized. For this study, the three independent variables were operationalized quantitatively. Students 'English proficiency was operationalized by the students' English proficiency marks. Like Gerber et al. [21], online instructor guidance was operationalized by counting the number of content-related and language-related messages posted by the instructors in the discussion forum. Also like Gerber et al. [21], online collaboration was operationalized by counting the number of content-related and language-related messages posted by the peer students in the discussion forum. The dependent variable students' learning was operationalized by test scores. Face validity is a way, though not a strong way, to access construct validity. Face validity is to look at the operationalization and see whether it appears to measure the construct. As stated by Stangor [5], face validity is "the extent to which the measured variable appears to be an adequate measure of the conceptual variable" (p. 96). For example, there was face validity for the questionnaire question 11 -students having more guidance from the instructors in a discussion forum were more likely than the other students in that forum to view the instructors' content-related and language-related guidance messages. Another way to access construct validity is convergent validity (or called construct validity by Babbie [7] which refers to "the degree to which a measure relates to other 
variables as expected within a system of theoretical relationships" (p. 156)). Convergent validity is obtained by examining the degree to which the operationalization converges on similar operationalizations. This validity can be evaluated using statistical procedures [16]. The learning effectiveness of the teaching methods obtained from questionnaire questions 12 to 14 could be used to statistically compare to the participants' ranks on the teaching methods in question 18 and tested if convergence occurred. Also, the data obtained from the questions 15 to 17 of the questionnaire could be used to statistically compare with those obtained from the questionnaire question 19. The researcher measured internal consistency reliability with Cronbach's coefficient alpha[20]. Each of the questionnaire questions 12 to 17 contains 5 similar items, each of which was responded to on a 7-point Likert's scale[29]ranging from "strongly agree" to "strongly disagree" with an additional "not available" point. The wording of the last 2 items is reversed to prevent response bias. For the first 3 items, the "strongly agree" option scores7, the "agree" option scores 6, and so on until the "strongly disagree" option scores1. For the last 2 items, scoring is reversed -the "strongly agree" option scores1, the "agree" option scores2, and so on until the "strongly disagree" option scores7. The "not available" option scores0 in all 5 items.Internal consistency is reflected by similar scores in similar items of a question and can be measured with Cronbach's coefficient alpha which should ideally be above 0.7 [11, 27]. Besides, to ensure that the participants understood the questions and gave reliable answers, the researcher gave explanation if needed when the participants filled the questionnaire in the meetings.

\subsection{Ethical Considerations}

The research was conducted at the college with the college's permission. At the beginning of the research, the research explained the importance, purpose, features, procedures and scope of the research to the participants. The participants were requested to give informed consent by completing the consent form. As the researcher said he was an insider in this research, that the researcher might encounter informant bias [14]. To minimize the informant bias, the guarantee of informant anonymity and emphasis of an independent researcher role were given to the participating students. Besides, the researcher avoided the authority relationship [25] by sampling the students taking the introductory IT course from the classes which were not taught by the researcher.To ensure confidentiality, the researcher stored the research data in highly secure computer systems protected with authorization and authentication mechanisms.

\section{Method}

The demographics of the sample of responding students are shown as follows: the respondents ages are between 18 and $23,95 \%$ of the respondents are Chinese, the remaining 5\% are other Asians, $100 \%$ of the respondents use English to learn in the college. In response to the questionnaire question 18, the majority of the respondents $(86.67 \%$, $73.33 \%$ and $86.67 \%$ in teaching method 1, 2 and 3respectively) ranked teaching method 1 as the most effective in learning and $(88 \%, 76 \%$ and $88 \%$ in teaching method 1,2 and 3 respectively) ranked teaching method 2 as the least effective in learning.In response to the questionnaire questions 12, 13 and 14, mean score of the seven items was computed (excluding 0 score for "not available" item). Table 1shows SPSS-computed Cronbach's coefficient alpha $\alpha \geq 0.7$ meaning that the internal consistency reliability of the items is acceptable [11,27] and shows the highest mean score $(\sqrt{ }$-marked)for question 12 indicating that teaching method 1 is the most effective in learning while the lowest mean score (s-marked)for question 13 indicating that teaching method 2 is the least effective in learning. These findings are consistent with survey results of questionnaire question 18 and Wong's findings[31].

Table. 1. Mean Scores and $\alpha$ of the Questions 12, 13 and 14 of the Questionnaire

\begin{tabular}{|c|c|c|c|}
\hline $\begin{array}{c}\text { Teaching Method the } \\
\text { Respondents were in }\end{array}$ & $\begin{array}{c}\text { Questionnaire } \\
\text { Question }\end{array}$ & Mean Score & $\begin{array}{c}\text { Cronbach's } \\
\text { Coefficient } \\
\text { Alpha } \boldsymbol{\alpha}\end{array}$ \\
\hline \multirow{3}{*}{1} & 12 & $5.84 \sqrt{\mathrm{s}}$ & 0.748 \\
\cline { 2 - 4 } & 13 & $3.69 \mathrm{~s}$ & 0.867 \\
\cline { 2 - 4 } & 14 & $4.78 \mathrm{x}$ & 0.875 \\
\hline \multirow{3}{*}{2} & 12 & $5.23 \sqrt{ }$ & 0.811 \\
\cline { 2 - 4 } & 13 & $3.25 \mathrm{~s}$ & 0.898 \\
\cline { 2 - 4 } & 14 & $4.06 \mathrm{x}$ & 0.866 \\
\hline \multirow{3}{*}{3} & 12 & $5.42 \sqrt{\mathrm{y}}$ & 0.878 \\
\cline { 2 - 4 } & 13 & $3.49 \mathrm{~s}$ & 0.893 \\
\cline { 2 - 4 } & 14 & $4.32 \mathrm{x}$ & 0.837 \\
\hline
\end{tabular}




\subsection{Correlation Results}

All correlation coefficients, as shown in Table 2, generated by SPS Positive and significant at 1\% level. Comparatively, students' English proficiency has a strong correlation (ie the largest $r=0.609, r=0.839$ and $r=0.689$ in teaching methods 1,2 and 3 respectively where $r$ is the linear correlation coefficient), online instructor guidance has a medium correlation and online collaboration has a weak correlation with students' test scores. The correlation between each predictor variable and the students' test scores in teaching method 2 is larger than that correlation in other teaching methods.

Table. 2. Comparison of Strengths of Correlation between the Students 'Test Scores and Each of Students' English Proficiency Marks, Online Instructor Guidance and Online Collaboration in Teaching Methods 1, 2 and 3

\begin{tabular}{|c|c|c|c|c|}
\hline \multirow{2}{*}{$\begin{array}{c}\text { Teaching } \\
\text { Method }\end{array}$} & \multicolumn{2}{|c|}{ Correlation Coefficient between Test Scores and } & \multirow{2}{*}{$\begin{array}{c}\text { Strength of } \\
\text { Correlation }\end{array}$} \\
\cline { 2 - 4 } & $\begin{array}{c}\text { Students' English } \\
\text { Proficiency Marks }\end{array}$ & $\begin{array}{c}\text { Online Instructor } \\
\text { Guidance }\end{array}$ & $\begin{array}{c}\text { Online } \\
\text { Collaboration }\end{array}$ & Weak \\
\hline 1 & 0.609 & 0.494 & 0.331 & Strong \\
\hline 2 & 0.839 & 0.586 & 0.405 & Medium \\
\hline 3 & 0.689 & 0.459 & Weak & \\
\hline $\begin{array}{c}\text { Strength of } \\
\text { Correlation }\end{array}$ & Strong & Medium & & \\
\hline
\end{tabular}

\subsection{Multiple Regression Results}

In simultaneous multiple regression, an interesting investigation is to look for which predictor variable has the stronger or lesser effect on students' test scores in each teaching method. The investigator looked at the standardized coefficients for different predictor variables as they had been converted to the same scale and therefore can be used for comparison $[15,34]$. The standardized regression coefficient $\beta$ represents the magnitude of effects in multiple regression. According to Keith's criteria in a similar research focus on school learning and learning performance [33, 34], students' English proficiency in Table 3 has a very large effect $(\beta=0.702)$ while online instructor guidance and online collaboration has a moderate effect $(\beta=0.214)$ and $\beta=0.173$ respectively) on the students' learning in teaching method 2.By comparing across different teaching methods, students' English proficiency has the largest effect $(\sqrt{ }$-marked) on the students' learning in teaching method 2 while the smallest effect (s -marked) in teaching method 1; online instructor guidance has the largest effect $(\sqrt{ }$-marked) on the students 'learning in teaching method 1 while the smallest effect (s-marked) on the students' learning in teaching method 2; and online collaboration has had the largest effect $(\sqrt{ }$-marked) on the students 'learning in teaching method 1 while the smallest effect (s-marked) on the students' learning in teaching method 2.

Table. 3. Magnitude of Effects of Predictor Variables on the Students' Test Scores

\begin{tabular}{|c|r|r|r|c|}
\hline \multirow{2}{*}{ Predictor Variables } & \multicolumn{3}{|c|}{ Beta $(\beta)$ in Teaching Method } & \multirow{2}{*}{ Magnitude of Effect } \\
\cline { 2 - 4 } & \multicolumn{1}{|c|}{$\mathbf{2}$} & \multicolumn{1}{|c|}{$\mathbf{3}$} & \\
\hline $\begin{array}{c}\text { Students' English } \\
\text { Proficiency Marks }\end{array}$ & $\begin{array}{r}.480 \\
\mathrm{~S}\end{array}$ & $\begin{array}{r}.702 \\
\sqrt{ }\end{array}$ & .578 & large \\
\hline Online Instructor Guidance & $\begin{array}{r}256 \\
\sqrt{ }\end{array}$ & $\begin{array}{r}.214 \\
\mathrm{~S}\end{array}$ & .242 & moderate \\
\hline Online Collaboration & $\begin{array}{r}192 \\
\sqrt{ }\end{array}$ & $\begin{array}{r}173 \\
\mathrm{~s}\end{array}$ & .174 & moderate \\
\hline
\end{tabular}

$\sqrt{ }$ - the largest influence among the three teaching methods

$\mathrm{s}$ - the smallest influence among the three teaching methods

The adjusted R2 indicates the combined effect of the predictor variables on the students' learning. Table 4compares the different magnitudes of the combined effect in these three teaching methods. The adjusted $\mathrm{R} 2=0.776$ indicates the predictor variables have the strongest combined effect on the students' test scores in teaching method 2 . The adjusted $\mathrm{R} 2=0.461$ indicates the smallest combined effect in teaching method 1 . 
Table. 4. Magnitude of Combined Effect of Predictor Variables on the Students' Test Scores

\begin{tabular}{|c|c|c|}
\hline Teaching Method & Adjusted $\boldsymbol{R}^{2}$ & Magnitude of Combined Effect \\
\hline 1 & 0.461 & Weak \\
\hline 2 & 0.776 & Strong \\
\hline 3 & 0.550 & Medium \\
\hline
\end{tabular}

In sequential multiple regression, the statistical significance and the magnitude of effect of the predictor variables depends on the order of entering the predictor variables into the regression equation [34]. As pointed out by Keith [34], the perceived importance can be used for deciding the order of entering variables into the regression equation. Based on the collected data from the questionnaire questions 15 to 17 and 19 in which students' English proficiency is ranked as the most important while online collaboration is ranked as the least important with SPSS-generated $\alpha \geq$ 0.7 meaning that there is internal consistency reliability of the items [11,27].From these results, the researcher first entered the most important predictor variable students' English proficiency marks, then online instructor guidance, and finally the least important predictor variable online collaboration into the sequential regression. The SPSS-generated model 1 refers to the first predictor variable students' English proficiency marks entered, model 2 includes students' English proficiency marks and online instructor guidance while model 3 contains all the three predictor variables. Based on the Beta $(\beta)$ values in the SPSS-generated coefficients tables and Keith's criteria [33, 34], Figure 1 shows the three tables that compare the magnitude of effects among the predictor variables in the three models. It shows the students 'English proficiency has the greatest effect on the students' test scores in the models.

\begin{tabular}{|c|c|c|c|c|}
\hline \multirow{2}{*}{ Predictor Variables } & \multicolumn{3}{|c|}{ Beta $(\beta)$ in Teaching Method } & \multirow{2}{*}{ Magnitude of Effect } \\
\hline & 1 & 2 & 3 & \\
\hline $\begin{array}{l}\text { Students' English } \\
\text { Proficiency Marks }\end{array}$ & $\begin{array}{r}.609 \\
\mathrm{~s}\end{array}$ & $\begin{array}{r}.839 \\
\sqrt{ }\end{array}$ & .689 & large \\
\hline
\end{tabular}

Model 1

\begin{tabular}{|c|c|c|c|c|}
\hline \multirow{2}{*}{ Predictor Variables } & \multicolumn{3}{|c|}{ Beta $(\beta)$ in Teaching Method } & \multirow{2}{*}{ Magnitude of Effect } \\
\hline & 1 & 2 & 3 & \\
\hline $\begin{array}{l}\text { Students' English } \\
\text { Proficiency Marks }\end{array}$ & $\begin{array}{r}.491 \\
\mathrm{~s}\end{array}$ & .722 & .605 & large \\
\hline $\begin{array}{c}\text { Online Instructor } \\
\text { Guidance }\end{array}$ & .302 & $\begin{array}{r}.260 \\
\mathrm{~s}\end{array}$ & 268 & moderate \\
\hline
\end{tabular}

Model 2

\begin{tabular}{|c|c|c|c|c|}
\hline \multirow{2}{*}{ Predictor Variables } & \multicolumn{3}{|c|}{ Beta $(\beta)$ in Teaching Method } & \multirow[b]{2}{*}{ Magnitude of Effect } \\
\hline & 1 & 2 & 3 & \\
\hline $\begin{array}{l}\text { Students' English } \\
\text { Proficiency Marks }\end{array}$ & $\begin{array}{r}.480 \\
\mathrm{~s}\end{array}$ & $\begin{array}{r}.702 \\
\sqrt{ }\end{array}$ & .578 & large \\
\hline $\begin{array}{l}\text { Online Instructor } \\
\text { Guidance }\end{array}$ & $\begin{array}{r}.256 \\
\sqrt{ }\end{array}$ & $\begin{array}{r}.214 \\
\mathrm{~s}\end{array}$ & .242 & moderate \\
\hline Online Collaboration & $\begin{array}{r}.192 \\
\sqrt{ }\end{array}$ & $\begin{array}{r}.173 \\
\mathrm{~s}\end{array}$ & .174 & moderate \\
\hline
\end{tabular}

Model 3

$\checkmark$ - the largest influence among the three teaching methods
$\mathrm{s}$ - the smallest influence among the three teaching methods

Figure. 1. Magnitude of Effects of Predictor Variables on the Students' Test Scoresin the Three Models in Teaching Methods 1, 2 and 3

\section{Discussion and Conclusion Remarks}

By realizing that the college students 'use of less familiar English to learn is an imperative characteristic in the Hong Kong higher education context and the college students are willing to learn through online discussion forum, the 
researchers grasped the insight into the effect of students' English proficiency, online instructor guidance and online collaboration on the college students' online learning. The analytical results show that each of the three predictor variables (i.e., students 'English proficiency, online instructor guidance and online collaboration) and a student's test score is positively correlated and there is a combined effect of these variables on the students' test scores. However, the cause-effect relationship between the variables and the students' learning was not confirmed. This provides implications for the next phase of further research in which qualitative interviews could be used as a follow-up to confirm the cause-effect relationship and obtain the participants' views on their experiences of using online education and how to develop effective learning in online education . Moreover, the proposed research can be extended to any other bilingual higher online education.

\section{References}

[1] A. Hwangand J. B. Arbaugh, Seeking feedback in blended learning: competitive versus cooperative student attitudes and their links to learning outcomes, Journal of Computer Assisted Learning, 25 (3), 280-293, 2009.

[2] A.B. Y. Wang and M. H. Newlin, Characteristics of students who enroll and succeed in psychology Web-classes, Journal of Educational Psychology, 92 (1), 137-143, 2000.

[3] B. G. Tabachnick, and L. S. Fidell, Using Multivariate Statistics, 5th Edition, Boston: Pearson / Allyn and Bacon, 2007.

[4] C. L. Aberson, D. E. Berger, M. R. Healy, D. J. Kyle and V. L. Romero, Evaluation of an interactive tutorial for teaching the central limit theorem, Teaching of Psychology, 27 (4), 289-292, 2000.

[5] C. Stangor, Research Methods for the Behavioral Sciences, 4th Edition, Belmont: Wadsworth / Cengage Learning, 2011.

[6] D. Y. F. Hoand J. A. Spinks, Multivariate prediction of academic performance by Hong Kong university students. Contemporary Educational Psychology, 10 (3), 249-259, 1985.

[7] E. Babbie, The Basics of Social Research, Belmont: Wadsworth / Cengage Learning, 2014.

[8] E. Fredericksen, A. Pickett, P. Shea, W. Pelzand K. Swan, Student satisfaction and perceived learning with on-line courses: principles and examples from the SUNY learning network, Journal of Asynchronous Learning Networks, 4 (2), 7-41, 2000.

[9] Education Commission, Education Commission Report No. 6, Hong Kong: Government Printer, 1996.

[10]Education Commission, Education Blueprint for the 21stCentury. Review of Academic System: Aims of Education, Hong Kong: Printing Department, 1999.

[11] J. C. Nunnelly, Psychometric Theory, 2nd Edition, New York: McGraw Hill, 1978.

[12] J. G. Graham, English language proficiency and the prediction of academic success, TESOL Quarterly, 21 (3), 505-521, 1987.

[13] J. Lim, M. Kim, S. S. Chen and C. E. Ryder, An empirical investigation of student achievement and satisfaction in different learning environments, Journal of Instructional Psychology, 35 (2), 113-119, 2008.

[14]J. Mercer, The challenges of insider research in educational institutions: wielding a double-edged sword and resolving delicate dilemmas, Oxford Review of Education, 33 (1), 1-17, 2007.

[15] J. Pallant, SPSS: Survival Manual: A Step by Step Guide to Data Analysis using SPSS for Windows, 3rdEdition, New York: McGraw-Hill, 2007.

[16] J. W. Creswell, Educational Research: Planning, Conducting, and Evaluating Quantitative and Qualitative Research, 3rd Edition, Upper Saddle River: Pearson, 2008.

[17] K. L. Chin, C. Bauerand V. Chang, The Use of Web-based Learning in Culturally Diverse Learning Environments, the 6thAustralian World Wide Web Conference, Cairns, Australia, 2000.

[18] K. Swan, Virtual interaction: design factors affecting student satisfaction and perceived learning in asynchronous online courses, Distance Education, 22 (2), 306-331, 2001.

[19] L. B. Christensen, R. B. Johnsonand L. Turner, Research Methods, Design and Analysis, 12th Edition, Upper Saddle River: Pearson, 2014.

[20]L. J. Cronbach, Coefficient alpha and the internal structure of tests, Psychometrika, 16,297-334, 1951.

[21]M. Gerber, S. Grundand G. Grote, Distributed collaboration activities in a blended learning scenario and the effects on learning performance, Journal of Computer Assisted Learning, 24 (3), 232-244, 2007.

[22] M. Saunders, P. Lewisand A. Thornhill, Research Methods for Business Students, 5th Edition, New York: FT / Prentice Hall, 2009. 
Simon Wong / Vol. 1, No. 2, December 2018, pp. 60-67

[23] N. A. Weiss, Introductory Statistics, 9th Edition, Boston: Addison-Wesley / Pearson, 2012.

[24] N. Li, D. Y. P. Leungand D. Kember, Medium of instruction in Hong Kong universities: the mis-match between espoused theory and theory in use, Higher Education Policy, 14, 293-312, 2001.

[25] P. Cooper, Field relations and the problem of authenticity in researching participants' perceptions of teaching and learning in classrooms, British Educational Research Journal, 19 (4), 323-338, 1993.

[26] R. A. Ellisand R. A. Calvo, Discontinuities in university student experiences of learning through discussions, British Journal of Educational Technology, 37 (1), 55-68, 2006.

[27]R. F. DeVellis, Scale Development: Theory and Applications, 2ndEdition, Thousand Oaks: Sage, 2003.

[28] R. K. Johnson, C. K. W. Shekand E. H. F. Law, Using English as the Medium of Instruction, Hong Kong: Longman, 1993.

[29] R. Likert, A technique for the measurement of attitudes, Archives of Psychology, 140, 5-53, 1932.

[30] S. Johnson, S. Aragon, N. Shaikand N. Palma-Rivas, Comparative analysis of learner satisfaction and learning outcomes in online and face-to-face learning environments, Journal of Interactive Learning Research, 11 (1), 29-49, 2000.

[31] S. Wong, An Evaluation of Pre-university Students' Performance Studying On-line Education in an Introductory Information Technology Course, International Conference of Education, Research and Innovation, Madrid, Spain, 2008.

[32] S. Wong, Factors Influencing On-line Learning: A Study Using Mixed Methods in a Hong Kong Higher Education Institution, Saarbrücken, Germany: LAMBERT Academic Publishing, 2012.

[33] T. Z. Keith, Structural equation modeling in school psychology, in Reynolds, C.R. and Gutkin, T.B. (Eds.) The Handbook of School Psychology, 3rd Edition, New York: Wiley, 1999.

[34] T. Z. Keith, Multiple Regression and Beyond, Boston: Pearson / Allyn and Bacon, 2006. 